Background Vasodilator-free indices of coronary stenosis severity require stability of resting coronary hemodynamics. It is unknown whether resting hemodynamics are sufficiently reproducible to be reliable over an extended period. We evaluate the long-term stability of resting and hyperaemic intracoronary pressure and flow velocity measurements over a 6-month period.

Methods 17 patients (mean age $55 \pm 12$ ), with 18 anatomically mild-to-moderate lesions (17 in the mid-left anterior descending artery and 1 circumflex artery) had invasive simultaneous pressure and flow velocity measurements made at rest and during intravenous adenosine infusion $(140 \mu \mathrm{g} / \mathrm{kg} / \mathrm{min})$. Measurements were repeated after 6 months at the same vessel location. Changes in coronary flow velocity and microcirculatory resistance were compared using Student $t$ test and the F test.

Results Mean flow velocity at rest was similar at baseline and 6 months $(22.2 \pm 8.5 \mathrm{~cm} / \mathrm{s}$ vs $21.6 \pm 8.5 \mathrm{~cm} / \mathrm{s}, \mathrm{p}=0.78)$; hyperaemic mean flow $(43.3 \pm 14.1 \mathrm{~cm} / \mathrm{s}$ vs $46.5 \pm 11.5 \mathrm{~cm} / \mathrm{s}, \mathrm{p}=0.47)$ similarly did not significantly change. The mean change between baseline and 6 months was $4 \%$ and $17 \%$ for resting and hyperaemic flow respectively and this was not significantly different $(p=0.27)$.

Peak coronary flow velocity was also similar at both time points at rest $(53.5 \pm 27.2 \mathrm{~cm} / \mathrm{s}$ vs $46.9 \pm 20.3 \mathrm{~cm} / \mathrm{s}, \mathrm{p}=0.38)$ and hyperaemia $(88.0 \pm 22.5 \mathrm{~cm} / \mathrm{s}$ vs $90.4 \pm 24.6 \mathrm{~cm} / \mathrm{s}, \mathrm{p}=0.75)$; the mean change was $3.0 \%$ and $9.0 \%$ respectively $(p=0.50)$. Microcirculatory resistance measured at rest was unchanged between baseline and 6 months at rest $(4.97 \pm 2.37 \mathrm{~mm} \mathrm{Hg} / \mathrm{cm} . \mathrm{s}$ vs $5.23 \pm 2.25 \mathrm{~mm} \mathrm{Hg} /$ $\mathrm{cm} . \mathrm{s}, \mathrm{p}=0.58)$ and during hyperaemia $(1.94 \pm 0.72$ vs $1.95 \pm 0.67$, $\mathrm{p}=0.98)$. The mean change in resistance was $17.8 \%$ at rest and $11.9 \%$ for hyperaemia, with no significant difference $(p=0.64)$.

Conclusions Coronary flow velocity and microcirculatory resistance when measured over rest or hyperaemia, vary to a similar degree over 6 months. This suggests that coronary haemodynamics during resting conditions are stable, consistent and reproducible in a manner similar to that observed during adenosine-mediated hyperaemia.

\title{
RELIABILITY OF RESTING CORONARY HAEMODYNAMICS WHEN REPEATED AFTER 6 MONTHS
}

S S Nijjer, ${ }^{1}$ P Eshtehardi, ${ }^{2}$ M T Corban, ${ }^{2}$ G Mekonnen, ${ }^{2}$ B Gogas, ${ }^{2}$ M C McDaniel, ${ }^{2}$ S Sen, ${ }^{1}$ R Petraco, ${ }^{1} \mathrm{~J}$ E Davies, ${ }^{1}$ H Samady ${ }^{2}{ }^{1}$ Imperial College London; ${ }^{2}$ Emory University 